\title{
Late presentation of RPE65 retinopathy in three siblings
}

\author{
Moustafa Magliyah • Amjad Ameen Saifaldein • Patrik Schatz
}

Received: 25 September 2019/Accepted: 30 December 2019/Published online: 10 January 2020

(C) The Author(s) 2020

\begin{abstract}
Purpose Gene therapy for RPE65 retinopathy has been recently approved. The purpose of this study was to assess retinal structure and function in 3 siblings presenting with late-stage RPE65 retinopathy and to assess the unmet need for such therapy in Saudi Arabia.

Methods Search of the retinal dystrophy registry at King Khaled Eye Specialist Hospital and clinical examination including multimodal retinal imaging, full-field electroretinography (ERG), dark adapted
\end{abstract}

Electronic supplementary material The online version of this article (https://doi.org/10.1007/s10633-019-09745-z) contains supplementary material, which is available to authorized users.

M. Magliyah · P. Schatz $(\bowtie)$

Vitreoretinal Division, King Khaled Eye Specialist

Hospital, Riyadh, Saudi Arabia

e-mail: patrik.schatz@med.lu.se

M. Magliyah

Ophthalmology Department, Prince Mohammed Medical

City, Aljouf, Saudi Arabia

\section{A. A. Saifaldein}

Ophthalmology Department, King Faisal Medical

Complex, Taif, Saudi Arabia

P. Schatz

Department of Ophthalmology, Clinical Sciences, Skane

University Hospital, Lund University, Lund, Sweden full-field stimulus sensitivity thresholds, and molecular genetic testing in 3 patients.

Results Nine (9) patients were identified with biallelic RPE65 mutations, corresponding to a prevalence rate of $9 / 187=5 \%$ among early onset retinal dystrophies. Of these, 3 siblings ( 2 male and 1 female) with RPE65 retinopathy were assessed in detail, because of an unusual, late presentation. They were all over 30 years old at the time of their most recent visits and had non-recordable ERGs. The 2 male siblings presented with poor vision and paracentral loss of the inner segment ellipsoid (ISe) and focal attenuation of the outer nuclear layer (ONL) in the macula. On the other hand, the female sibling presented with 20/100 vision with preserved foveal ISe and intact ONL throughout the macula and significantly lower light sensitivity thresholds compared to her male siblings. A homozygous missense p.Arg91Trp mutation in RPE65 was identified in all. All patients were eligible for gene therapy, demonstrating a central retinal thickness of more than 100 microns on repeated examinations.

Conclusions RPE65 retinopathy seems to be relatively common on the Arabian peninsula, and in addition it may be underdiagnosed. To the best of our knowledge, this is the first detailed presentation, including multimodal retinal imaging and electrophysiological assessment, of such patients from this region. Patients with late presentation of RPE65 retinopathy may be eligible for gene therapy, in terms of remaining retinal function and structural 
preservation. The therapeutic window of such therapy remains to be determined.

Keywords RPE65 - Gene therapy $\cdot$ Multimodal retinal imaging

\section{Introduction}

Leber's congenital amaurosis (LCA) is a group of congenital retinal dystrophies which usually present before 6 months of age with severe visual impairment and nystagmus [1-5]. Inheritance is autosomal recessive; however, dominant inheritance has been reported in cases with $C R X$ and IMPDHI mutations [6-11].

Mutations in several genes have been shown to cause recessive LCA (reviewed in https://www.ncbi. nlm.nih.gov/books/NBK1298/). Recessive RPE65 retinopathy has traditionally been grouped with LCA; however, it differs because useful vision and central retinal structure may be preserved for several years [12]. Together with slow progression, this makes it a potential candidate for gene therapy [13]. RPE65 encodes the isomerohydrolase of the visual cycle, and dysfunction of this enzyme leads to an insufficient regeneration of the chromophore linked to opsin in the photoreceptors. This also leads to a slowly progressive degeneration of the retina. Typically the full-field ERG is non-recordable even at the time of initial diagnosis and therefore other form of assessment of progression, or of therapeutic response after gene replacement therapy, is needed, such as visual fields, visual acuity, full-field sensitivity testing (FST) and multimodal retinal imaging, including assessment of preservation of retinal layers and retinal thickness.

In this study, we describe the clinical, electrophysiological and molecular genetic findings in 3 siblings who presented with late-stage RPE65 retinopathy, in light of the recently approved gene therapy for this condition. To the best of our knowledge, such assessment including detailed analysis of retinal structure and function has not been described for this disease in the Arabian peninsula. The recently approved gene replacement therapy is expensive and resource demanding and therefore may require significant planning and coordination. Thus in addition, we estimate the prevalence of this condition in the region, in preparation for future gene therapy.

\section{Methods}

Informed consent was obtained, and the study was approved by an institutional review board at King Khaled Eye Specialist Hospital, which is a nationwide tertiary referral centre, and at times also accepts referred patients from neighbouring countries. Ophthalmic examination including multimodal retinal imaging and full-field electroretinography (ERG) was done as described by us and others previously $[14,15]$. Goldman visual fields were performed using objects V4 and III4.

ERG (Nicolet Biomedical Instruments, Madison, Wisconsin, USA) was obtained as follows, in dark adapted and light adapted state according to ISCEV standards [15], with a few modifications as follows. Dark adaptation was performed for $30 \mathrm{~min}$, and dilatation of the pupils was obtained with topical cyclopentolate $1 \%$ and metaoxedrine $2.5 \%$. After topical anaesthesia, a Burian Allen bipolar contact lens was placed on the cornea and a ground electrode was applied to the forehead. Responses were obtained stimulating with single full-field flash $(30 \mathrm{~ms})$ with blue light $\left(0.81 \mathrm{~cd} \mathrm{~s} / \mathrm{m}^{2}\right.$ : rod response) and with white light $\left(10.02 \mathrm{~cd} \mathrm{~s} / \mathrm{m}^{2}\right.$ : combined rod-cone response). In addition, the dark adapted cone response was measured after stimulation with dim red light $\left(3.93 \mathrm{~cd} \mathrm{~s} / \mathrm{m}^{2}\right)$. Photopic responses were obtained with a background illumination of $3.4 \mathrm{~cd} \mathrm{~s} / \mathrm{m}^{2}$ in order to saturate the rods.

Dark adapted full-field stimulus thresholds (FST) were assessed using white light and the Espion ColorDome $^{\mathrm{TM}}$ system (Diagnosys LLC). FST measures the light sensitivity over the whole visual field and is therefore not affected by nystagmus. A meaningful change has been suggested as $10 \mathrm{~dB}$ or 1 $\log$. Results were presented as log candela seconds per square meter $\left(\log \mathrm{cd} \mathrm{s} / \mathrm{m}^{2}\right)$.

A targeted next-generation sequencing (NGS) was performed using two panels in two different laboratories; a retinal dystrophy panel at molecular genetics laboratory at King Faisal Specialist Hospital (KFSH) [16], and a LCA panel in the Bioscientia Human Genetics laboratory (Bioscientia, Ingelheim, Germany) which includes GUCY2D, RPE65, SPATA7, AIPL1, LCA5, RPGRIP1, CRX, CRB1, CEP290, IMPDH1, RD3, RDH12, LRAT, MERTK and TULP1.

Finally, we searched a newly established retinal dystrophy registry at King Khaled Eye Specialist 
Hospital, which includes most patients seen in specially designed "retinal dystrophy clinics" since 2014, at the time of which electronical medical records were implemented in the hospital, for "RPE65", in order to estimate the prevalence of RPE65 retinopathy in the region.

\section{Results}

The retinal dystrophy registry at this time included a total of 789 patients. Of these, 187 patients for whom NGS had been carried out were diagnosed with early onset retinal dystrophy. Nine (9) of these patients had biallelic RPE65 mutations, arriving at an estimated prevalence rate of $9 / 187=5 \%$ among early onset retinal dystrophies.

Three of the affected patients, 3 siblings, had an atypical late presentation of the disease, while the other 6 patients had all been diagnosed before reaching 10 years of age. The 3 patients were further examined in detail, because of the unusual late presentation, with the aim of assessing the extent, if any, of remaining retinal function. The patients were belonging to a family of 8 siblings ( 3 brothers and 5 sisters) with a positive history of parental consanguinity. All three, 2 male and 1 female (patients 1, 2 and 3), aged 32, 36 years and 34 years old, respectively, at most recent follow-up, were homozygous for the c.271C $>\mathrm{T}$ (p.Arg91Trp) mutation in RPE65. The mutations were confirmed by 2 independent molecular genetic institutions (KFSH for patients 1 and 3 and Bioscientia for patient 2); however, other family members were not available for mutation segregation analysis or clinical examination.

All 3 had experienced nystagmus and night blindness since early childhood, with gradual and progressive visual loss. They presented 4 years ago with best corrected visual acuity (BCVA) of 20/400 in both eyes of patients 1 and 2, and 20/80 in patient 3. Patients 1 and 2 showed prominent peripheral retinal pigmentation, with less peripheral changes in patient 3. Central macular retinal layers showed signs of paracentral loss of the inner segment ellipsoid (ISe) and outer nuclear layer (ONL) compromise, more severe in patients 1 and 2, whereas the ONL was preserved throughout the macula in patient 3 (Figs. 1, 2, 3). ERG was nonrecordable in all (Fig. 4 demonstrates the ERG obtained from Patient 1, and Supplemental document
1 demonstrates the ERGs of Patients 2 and 3). After 4 years of follow-up, BCVA was reduced to light perception (LP) in both eyes of the male patients and to $20 / 100$ in the female patient.

In patient 3, an ETDRS OCT map was possible in the right eye on 2 separate occasions, separated by 30 months, showing an apparent decline of the central subfield thickness from 252 to $196 \mu \mathrm{m}$, while the visual acuity remained stable during the same period, ranging between 20/100 and 20/80 during a total of 7 visits. Retinal thickness was well above $100 \mu \mathrm{m}$ in all subfields, in both eyes. In the other 2 patients, a quantitative approach over time including analysis of potential changes of retinal thickness was not possible because of insufficient fixation during obtaining OCT images in most of the visits, due to nystagmus; however, available thickness measurements from single-line horizontal transfoveal scans demonstrated a retinal thickness well above $100 \mu \mathrm{m}$ along the scanned lines.

Visual fields were severely constricted to less than 10 degrees with the largest object in Patients 1 and 2, while Patient 3 had constricted fields to less than 10 degrees with the III4 object and less than 60 degrees horizontally and less than 50 degrees vertically with the largest V4 object. Mean (of right and left eyes for each patient) FST thresholds were 2.7, 1.9 and $-1.8 \log \mathrm{cd} \mathrm{s} / \mathrm{m}^{2}$, for Patients 1, 2 and 3, respectively.

Fundus autofluorescence demonstrated a generalized loss of autofluorescence, where the discs appeared relatively bright on a dark background; however, a trace of preserved autofluorescence could be noticed within the vascular arcades, compared to the periphery, especially in Patient 3 (Supplemental document 2).

\section{Discussion}

We describe a late presentation of RPE65 retinopathy in 3 siblings with the homozygous p.Arg91Trp mutation. King Khaled Eye Specialist Hospital is a major tertiary referral centre on the Arabian peninsula, and we have so far identified 9 patients with RPE65 retinopathy during our experience of more than 5 years in the hospital. This estimates the minimum prevalence of RPE65 retinopathy among retinal dystrophies at $5 \%$ which is higher by a factor of 5 


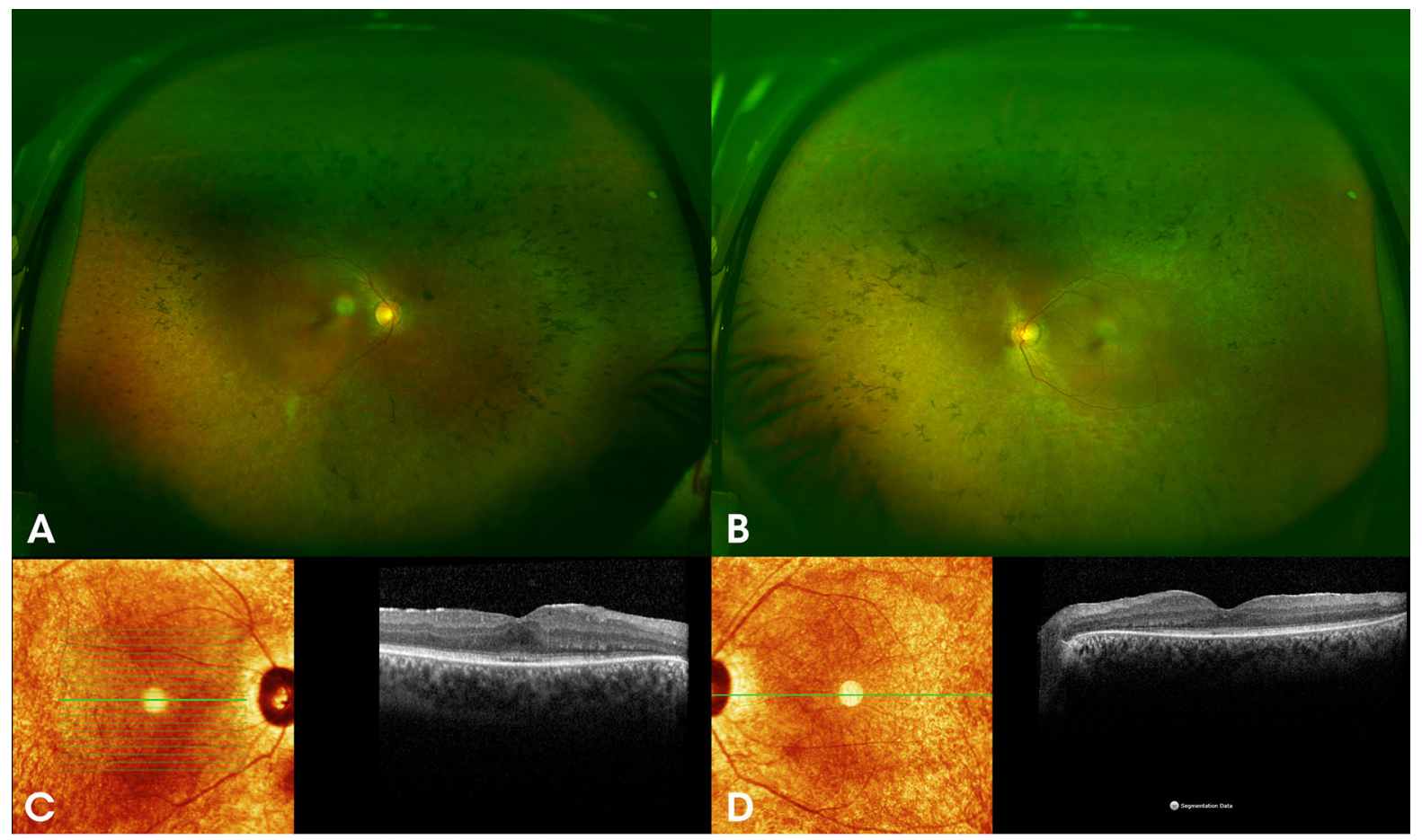

Fig. 1 A and $\mathbf{B}$ colour fundus photographs of both eyes of a 32-year-old male patient (patient 1) with the homozygous c.271C > T (p.Arg91Trp) mutation in RPE65, showing peripheral pigment depositions (bone spicules), attenuated blood vessels and oval shaped hyperopic discs with temporal pallor.

compared to a previous study in the US population [17]. This may be due to a high rate of consanguineous marriage. Furthermore, the condition may be underrecognized and underdiagnosed due to limited availability to perform genetics testing, cost and failure to recognize the phenotype. However with the recently approved gene therapy for this condition, it is likely that the awareness of this condition, among ophthalmologists and patients alike, will increase, which may lead to identification of significantly greater number of patients.

We assessed 3 of these patients further, carrying the p.Arg91Trp mutation, which has been described previously in RPE65 retinopathy [18-20]. Table 1 shows the phenotypic features of all patients with p.Arg91Trp mutation in RPE65 including the three siblings in this study. Features in common for these patients include nystagmus, hyperopia, and nonrecordable ERGs. Ambulatory vision was maintained in the female sibling (20/100 OU), similar to two patients described by Thompson et al. [20]. This could
Spectral domain optical coherence tomography (SD-OCT) of both eyes $\mathbf{C}$ and $\mathbf{D}$ shows paracentral loss of the inner segment ellipsoid (ISe) and focal attenuation of the outer nuclear layer (ONL)

be due to a preserved RPE65 activity which can produce low amounts of 11-cis retinal in patients with the missense p.Arg91Trp mutation, allowing for better cone and rod function compared to patients with RPE65 null mutations, as suggested in experimental work with mice with corresponding knock-in mutation, compared to RPE65 null mice [21]. This may also account for some degree of preservation of fundus autofluorescence (Supplemental document 2). On the other hand, the 2 male patients in this study, similar to one of the patients described by Thompson et al., had poorer vision, which was noted also in the patient described by Habibi et al. [18] and was correlated with foveal atrophy on SD-OCT. The integrity of the ONL is a prominent indicator of photoreceptors function and was advised to be included in the evaluation for gene therapy [22].

Recently, Russell et al. [23] conducted a phase 3 randomized controlled trial evaluating the efficacy and safety of gene therapy for patients with RPE65 retinopathy, in which four patients were compound 


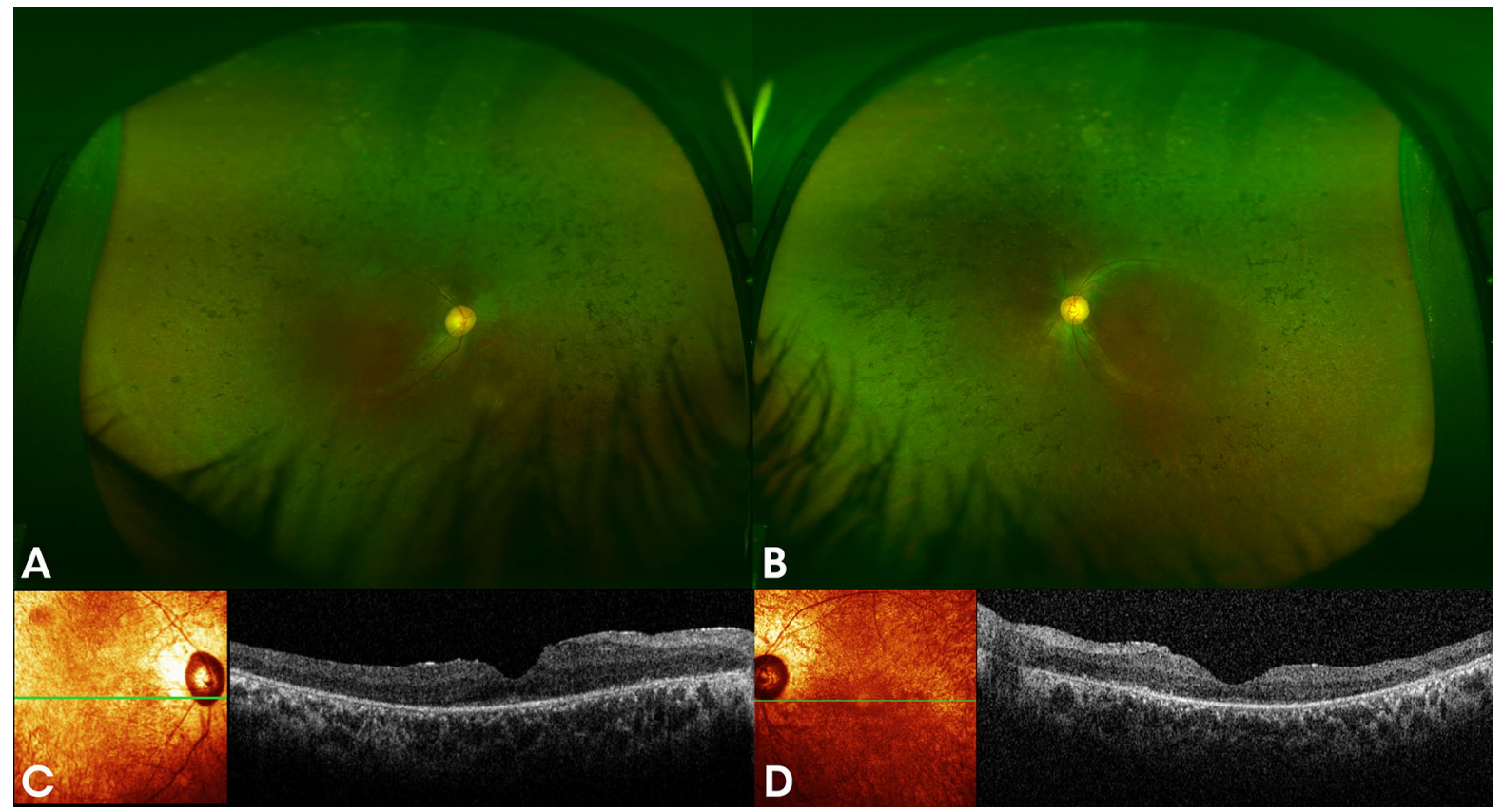

Fig. $2 \mathbf{A}$ and $\mathbf{B}$ colour fundus photographs of both eyes of a 36-year-old male (patient 2), sibling of patient 1 , with the homozygous c.271C $>\mathrm{T}$ (p.Arg91Trp) mutation in RPE65 showing bone spicules, attenuated blood vessels and oval

heterozygous for the Arg91Trp mutation (and the mutations IVS7 $+2 \mathrm{~T}>\mathrm{A}$, Trp402Stop [2 patients] and Arg91Gln, respectively). Table 2 shows that for this subgroup of patients, the average improvement in BCVA was 10 letters, which was similar to the mean for all patients (9 letters), while the average of illuminance level difference for passing the multiluminance mobility test (MLMT, the primary outcome of the study) was slightly less than the illuminance level difference mean for all patients (Table 2) [23].

In this study, in spite of late presentation, all 3 patients with the homozygous Arg91Trp mutation in RPE65 maintained a central retinal thickness of more than 100 microns and also fulfilled other eligibility criteria, including the level of visual acuity, for gene replacement therapy. On the other hand, there was variability regarding the stage of disease, as observed by, for example, visual fields and remaining autofluorescence, among the 3 patients. Patient 3 presented with the least advanced disease stage, based on these assessments. Furthermore, based on the FST results, Patient 3 might be the best candidate, because of relatively preserved dark adapted sensitivity thresholds, presenting results that imply a sensitivity in the shaped hyperopic discs with temporal pallor. Spectral domain optical coherence tomography (SD-OCT) of both eyes $\mathbf{C}$ and D shows paracentral loss of the inner segment ellipsoid (ISe) and attenuation of the outer nuclear layer (ONL)

upper range compared to other patients with "LCA" who were examined previously in the literature by this modality, albeit the thresholds were significantly elevated compared to normal subjects who were reported to have a mean of $-4.3 \log \mathrm{cd} \mathrm{s} / \mathrm{m}^{2}$ [24]. Thus, gene replacement therapy should be primarily be considered for Patient 3 once available in Saudi Arabia. This illustrates that FST is more appropriate than ERG as a measure of eligibility for and therapeutic response to currently available gene augmentation therapy, where the gene and its viral vector are delivered by subretinal injection in a limited area of the central retina only, and thus any improvement of retinal function in such a limited area may not be detected using ERG. Thus, albeit the ERG is a very powerful tool and is essential in diagnosing retinal dystrophies, the method has a limited sensitivity, and needs to be complemented with other more sensitive measures when evaluating potential treatments for retinal dystrophies.

Limitations of this study include the few number of patients examined and lack of mutation segregation analysis and clinical examination of other family members. On the other hand, this is the first report of clinical findings including multimodal retinal imaging 


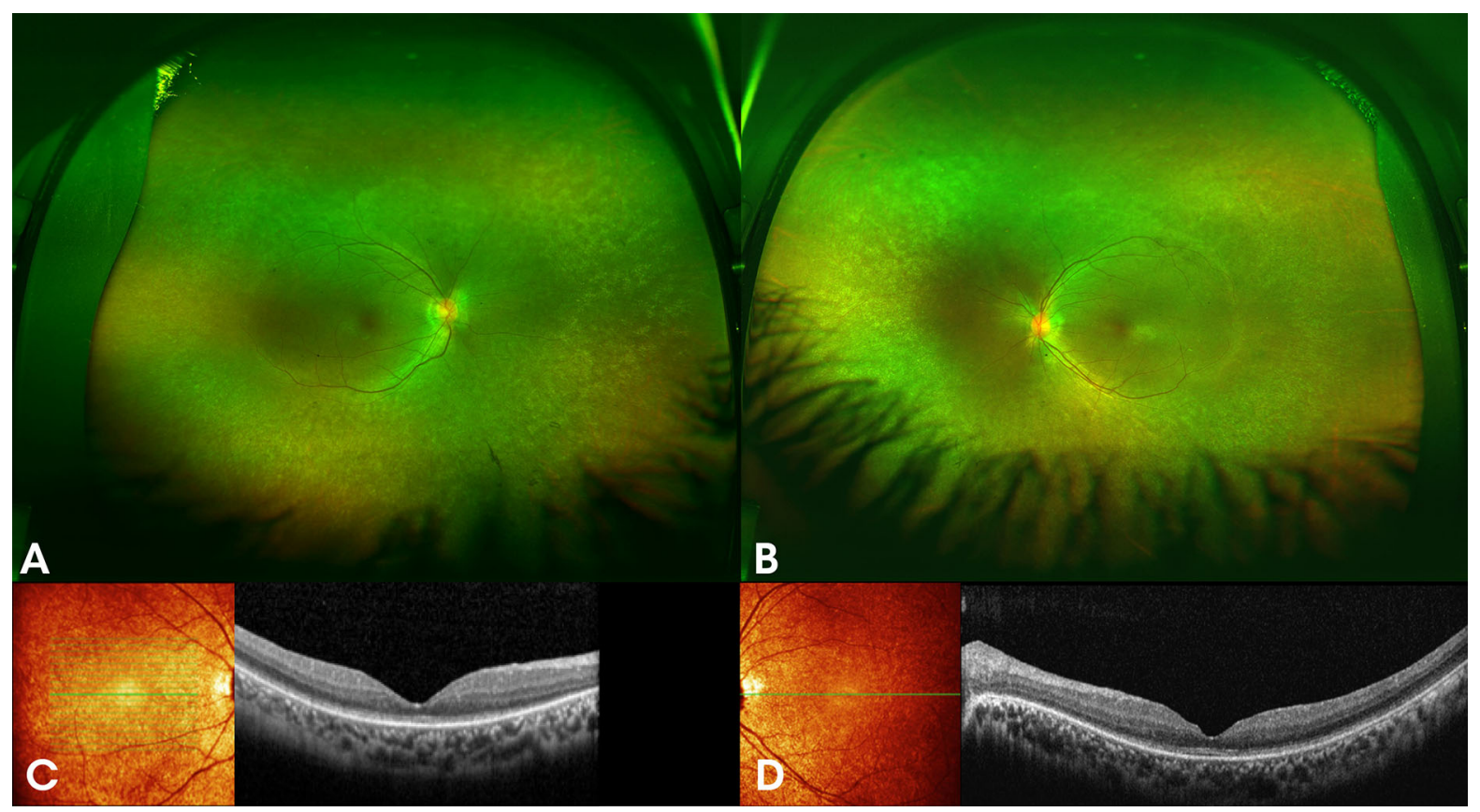

Fig. $3 \mathbf{A}$ and $\mathbf{B}$ colour fundus photographs of both eyes of a 34-year-old female (patient 3), a sibling of previous two patients, with the homozygous c.271C $>\mathrm{T}$ (p.Arg91Trp) mutation in RPE65, showing peripheral depigmentation, hyperopic oval shaped discs and attenuated vessels. Spectral domain optical coherence tomography (SD-OCT) of both eyes $\mathbf{C}$ and D shows paracentral loss of the inner segment ellipsoid (ISe) and relatively intact outer nuclear layer (ONL) throughout the macula
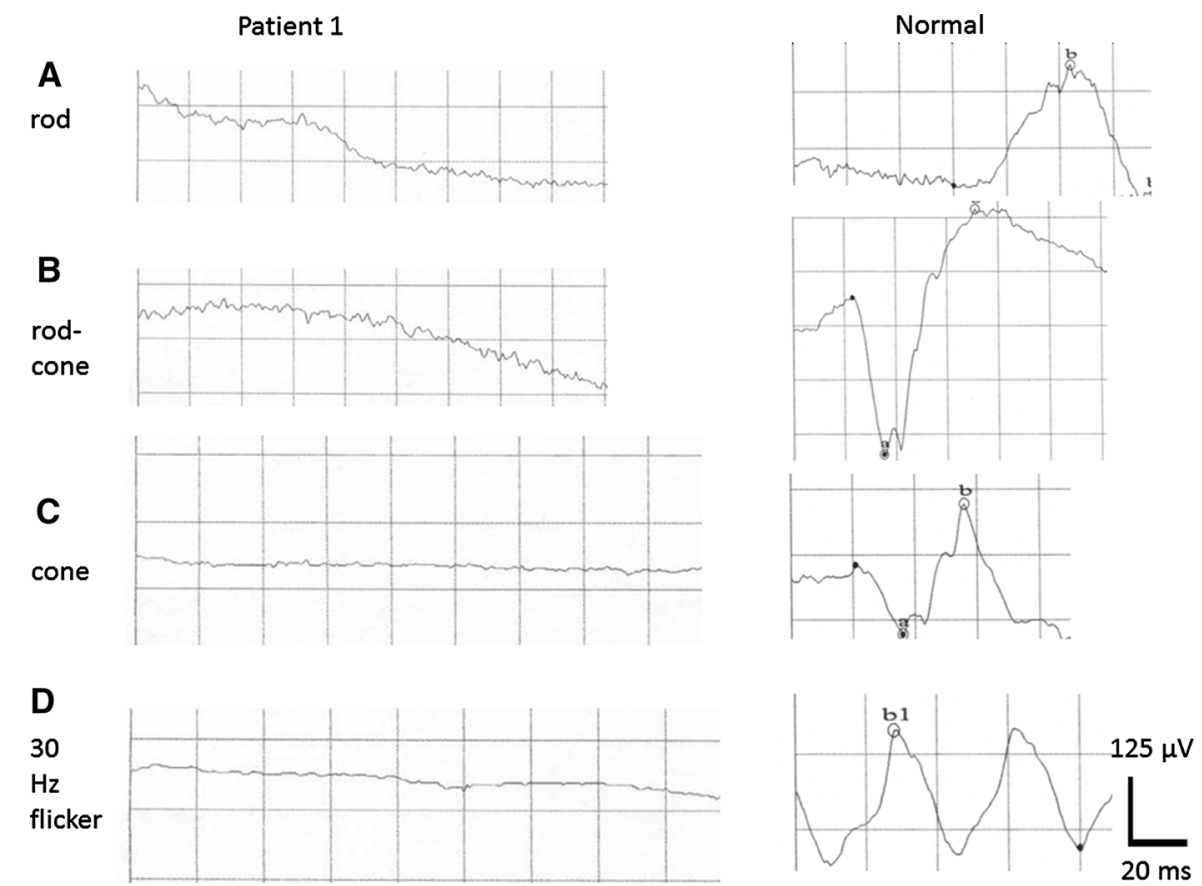

Fig. 4 Full-field electroretinogram (ERG) in Patient 1 with RPE65 retinopathy, at the age of 30 years, shows no recordable responses. A normal ERG is shown as a reference in the right column 
Table 1 Phenotypic features of patients with the p.Arg91Trp mutation in the RPE65 gene

\begin{tabular}{|c|c|c|c|c|c|}
\hline Study & BCVA & Refraction & Fundus & OCT & ERG \\
\hline \multirow[t]{3}{*}{$\begin{array}{l}\text { Magliyah et al. } \\
\text { this article }\end{array}$} & $\begin{array}{l}\text { LP OU } \\
\text { Nystagmus } \\
\text { Age } 36 \text { years }\end{array}$ & $\begin{array}{l}+1-1.00 X 180 \\
\text { OU }\end{array}$ & $\begin{array}{l}\text { Diffuse bone spicules, } \\
\text { attenuated vessels, oval shaped } \\
\text { hyperopic disc with temporal } \\
\text { pallor }\end{array}$ & $\begin{array}{l}\text { Paracentral loss } \\
\text { of ISe, } \\
\text { attenuation of } \\
\text { ONL }\end{array}$ & $\begin{array}{l}\text { Non- } \\
\text { recordable }\end{array}$ \\
\hline & $\begin{array}{l}\text { LP OU Nystagmus } \\
\text { Age } 32 \text { years }\end{array}$ & $\begin{array}{l}+3.50 \\
-1.00 \times 90 \mathrm{OU}\end{array}$ & $\begin{array}{l}\text { Diffuse bone spicules, } \\
\text { attenuated vessels, oval shaped } \\
\text { hyperopic disc with temporal } \\
\text { pallor }\end{array}$ & $\begin{array}{l}\text { Paracentral loss } \\
\text { of ISe, } \\
\text { attenuation of } \\
\text { ONL }\end{array}$ & $\begin{array}{l}\text { Non- } \\
\text { recordable }\end{array}$ \\
\hline & $\begin{array}{l}20 / 100 \\
20 / 100 \\
\text { Nystagmus } \\
\text { Age } 34 \text { years }\end{array}$ & $\begin{array}{l}+1.75 \\
-1.00 \times 90 \\
\text { OU }\end{array}$ & $\begin{array}{l}\text { Peripheral depigmentation, } \\
\text { hyperopic oval shaped disc, } \\
\text { attenuated vessels }\end{array}$ & $\begin{array}{l}\text { Paracentral loss } \\
\text { of ISe, intact } \\
\text { ONL }\end{array}$ & $\begin{array}{l}\text { Non- } \\
\text { recordable }\end{array}$ \\
\hline Habibi et al. [18] & $\begin{array}{l}<20 / 200 \\
\text { Age } 14 \text { years }\end{array}$ & N/A & $\begin{array}{l}\text { Depigmented deposits in the mid } \\
\text { periphery, Mild optic atrophy, } \\
\text { Narrowing of the vessels }\end{array}$ & $\begin{array}{l}\text { Macular } \\
\text { atrophy }\end{array}$ & \\
\hline \multirow[t]{3}{*}{ Li et al. [19] } & $\begin{array}{l}\text { Nystagmus } \\
\text { Age N/A }\end{array}$ & $\begin{array}{l}+3.00 \\
+1.00 \mathrm{X} 90 \mathrm{OU}\end{array}$ & $\begin{array}{l}\text { Peripheral depigmentation, oval } \\
\text { discs, mild optic atrophy and } \\
\text { vascular attenuation }\end{array}$ & N/A & $\begin{array}{l}\text { Non- } \\
\text { recordable }\end{array}$ \\
\hline & $\begin{array}{l}\text { Nystagmus } \\
\text { Age N/A }\end{array}$ & $\begin{array}{l}+1.50 \\
+1.00 \times 90 \mathrm{OU}\end{array}$ & $\begin{array}{l}\text { Minimal peripheral pigment } \\
\text { changes; oval hyperopic disc }\end{array}$ & N/A & $\begin{array}{l}\text { Non- } \\
\text { recordable }\end{array}$ \\
\hline & $\begin{array}{l}\text { Nystagmus } \\
\text { Age N/A }\end{array}$ & $\begin{array}{l}+0.25 \\
+1.50 \times 90 \mathrm{OU}\end{array}$ & $\begin{array}{l}\text { Minimal peripheral pigmentary } \\
\text { changes; hyperopic full discs }\end{array}$ & N/A & $\begin{array}{l}\text { Non- } \\
\text { recordable }\end{array}$ \\
\hline \multirow[t]{3}{*}{$\begin{array}{l}\text { Thompson et al. } \\
\text { [20] }\end{array}$} & $\begin{array}{l}\text { 20/100 OU, Nystagmus } \\
\text { Age } 7 \text { years }\end{array}$ & N/A & N/A & N/A & $\begin{array}{l}\text { Non- } \\
\text { recordable }\end{array}$ \\
\hline & $\begin{array}{l}\text { 20/100 OU Nystagmus } \\
\text { Age } 6 \text { years }\end{array}$ & N/A & N/A & N/A & $\begin{array}{l}\text { Non- } \\
\text { recordable }\end{array}$ \\
\hline & $\begin{array}{l}\text { LP OU } \\
\text { Age } 23 \text { years }\end{array}$ & N/A & N/A & N/A & $\begin{array}{l}\text { Non- } \\
\text { recordable }\end{array}$ \\
\hline
\end{tabular}

$\overline{B C V A}$ best corrected visual acuity, $H M$ hand motion, $L P$ light perception, $O U$ both eyes, $O N L$ outer nuclear layer, $I S e$ inner segment ellipsoid, $O C T$ optical coherence tomography, ERG full-field electroretinography, N/A not analysed, $y$ years

Table 2 Results of gene therapy of patients with the Arg91Trp and (in a compound heterozygous, biallelic mode) IVS7 +2 T > A, Trp402Stop, Trp402Stop, Arg91Gln mutations,

\begin{tabular}{|c|c|c|c|c|c|c|c|c|}
\hline Patient & Age & Gender & $\begin{array}{l}\text { Average } \\
\text { BCVA at } \\
\text { baseline }\end{array}$ & $\begin{array}{l}\text { Average } \\
\text { BCVA after } \\
1 \text { year }\end{array}$ & $\begin{array}{l}\text { No. of } \\
\text { letters } \\
\text { gained }\end{array}$ & $\begin{array}{l}\text { Illuminance (lux) } \\
\text { passing level at } \\
\text { baseline }\end{array}$ & $\begin{array}{l}\text { Illuminance (lux) } \\
\text { passing level at } \\
1 \text { year }\end{array}$ & $\begin{array}{l}\text { Change } \\
\text { Score }\end{array}$ \\
\hline 1 & 6 & Male & $20 / 125$ & $20 / 100$ & 8 & 4 & 1 & 1 \\
\hline 2 & 34 & Female & $20 / 800$ & $20 / 400$ & 13 & 125 & 50 & 1 \\
\hline 3 & 44 & Female & $20 / 800$ & $20 / 500$ & 11 & 125 & 10 & 2 \\
\hline 4 & 19 & Female & $20 / 400$ & $20 / 250$ & 8 & 125 & 250 & -1 \\
\hline
\end{tabular}

The Illuminance passing level refers to the level at which the patients were able to perform and pass the multiluminance mobility test, which was the primary outcome parameter [23]

$B C V A$ best corrected visual acuity respectively, from top to bottom, in RPE65 in the voretigene neparvovec phase 3 gene therapy trial by Russel et al. [23] 
in late-stage RPE65 retinopathy due to this specific homozygous mutation, confirming eligibility for gene therapy for some patients, even with late presentation. A further novelty with this study is that RPE65 retinopathy may be relatively common in Saudi Arabia, which may necessitate mobilization of economical resources and further diagnostic and operational skill in ophthalmic health care in the region. The therapeutic window for such therapy remains to be determined.

Acknowledgements Open access funding provided by Lund University.

Authors' contribution MM, AS, and PS designed the study; MM, AS, and PS conducted the study; and MM, AS, and PS were involved in collection, management, analysis, and interpretation of the data. MM, AS, and PS were involved in preparation, review and final approval of the manuscript. We thank Mr Adolph Cabanas at Design and Publications, King Khaled Eye Specialist Hospital, for skillful technical assistance with preparation of figures. Part of this material was presented at the Euretina meeting in Paris on September 5-8, 2019.

Funding No funding was received for this research.

\section{Compliance with ethical standards}

Conflict of interest Each of the authors declares that they have no conflicts of interest.

Statement of human rights All procedures performed in studies involving human participants were in accordance with the ethical standards of the IRB of King Khaled Eye Specialist Hospital and with the 1964 Helsinki Declaration and its later amendments.

Statement on the welfare of animals This article does not contain any studies with animals performed by any of the authors.

Informed consent Informed consent was obtained from all individual participants included in the study.

Open Access This article is licensed under a Creative Commons Attribution 4.0 International License, which permits use, sharing, adaptation, distribution and reproduction in any medium or format, as long as you give appropriate credit to the original author(s) and the source, provide a link to the Creative Commons licence, and indicate if changes were made. The images or other third party material in this article are included in the article's Creative Commons licence, unless indicated otherwise in a credit line to the material. If material is not included in the article's Creative Commons licence and your intended use is not permitted by statutory regulation or exceeds the permitted use, you will need to obtain permission directly from the copyright holder. To view a copy of this licence, visit http://creativecommons.org/licenses/by/4.0/.

\section{References}

1. Heckenlively JR, Foxman SG, Parelhoff ES (1988) Retinal dystrophy and macular coloboma. Doc Ophthalmol 68:257-271

2. Mizuno K, Takei Y, Sears ML et al (1977) Leber's congenital amaurosis. Am J Ophthalmol 83:32-42

3. Noble KG, Carr RE (1978) Leber's congenital amaurosis: a retrospective study of 33 cases and a histopathological study of one case. Arch Ophthalmol 96:818-821

4. Margolis S, Scher BM, Carr RE (1977) Macular colobomas in Leber's congenital amaurosis. Am J Ophthalmol 83:27-31

5. Francois J (1968) Leber's congenital tapeto-retinal degeneration. Int Ophthalmol Clin 8:929-947

6. Heckenlively JR (1988) Autosomal dominant retinitis pigmentosa. In: Retinitis Pigmentosa. JB Lippincott Co, Philadelphia, pp 125-149

7. Sorsby A, Williams CE (1960) Retinal aplasia as a clinical entity. BMJ 1:293-297

8. Sohocki MM, Sullivan LS, Mintz-Hittner HA et al (1998) A range of clinical phenotypes associated with mutations in CRX, a photoreceptor transcription-factor gene. Am J Hum Genet 63:1307-1315

9. Rivolta C, Berson EL, Dryja TP (2001) Dominant Leber congenital amaurosis, cone-rod degeneration, and retinitis pigmentosa caused by mutant versions of the transcription factor CRX. Hum Mutat 18:488-498

10. Arcot Sadagopan K, Battista R, Keep RB, Capasso JE, Levin AV (2015) Autosomal-dominant Leber congenital amaurosis caused by a heterozygous CRX mutation in a father and son. Ophthalmic Genet 36:156-159

11. Bowne SJ, Sullivan LS, Mortimer SE et al (2006) Spectrum and frequency of mutations in IMPDH1 associated with autosomal dominant retinitis pigmentosa and leber congenital amaurosis. Invest Ophthalmol Vis Sci 47:34-42

12. Jacobson SG, Aleman TS, Cideciyan AV et al (2007) Human cone photoreceptor dependence on RPE65 isomerase. Proc Natl Acad Sci USA 104:15123-15128

13. Cai X, Conley SM, Naash MI (2009) RPE65: role in the visual cycle, human retinal disease, and gene therapy. Ophthalmic Genet 30:57-62

14. Schatz P, Abdalla Elsayed MEA, Khan AO (2017) Multimodal imaging in CABP4-related retinopathy. Ophthalmic Genet 38:459-464

15. McCulloch DL, Marmor M, Brigell MG et al (2015) ISCEV Standard for full-field clinical electroretinography (2015 update). Doc Ophthalmol 130:1-12

16. Saudi Mendeliome Group (2015) Comprehensive gene panels provide advantages over clinical exome sequencing for Mendelian diseases. Genome Biol 16:134

17. Stone EM, Andorf JL, Whitmore SS, DeLuca AP, Giacalone JC, Streb LM, Braun TA, Mullins RF, Scheetz TE, Sheffield VC, Tucker BA (2017) Clinically focused molecular investigation of 1000 consecutive families with inherited retinal disease. Ophthalmology 124:1314-1331

18. Habibi I, Chebil A, Falfoul Y et al (2016) Identifying mutations in Tunisian families with retinal dystrophy. Sci Rep 6:37455 
19. Li Y, Wang H, Peng J et al (2008) Mutation survey of known LCA genes and loci in the Saudi Arabian population. Invest Ophthalmol Vis Sci 50:1336-1343

20. Thompson DA, Gyurus P, Fleischer LL et al (2000) Genetics and phenotypes of RPE65 mutations in inherited retinal degeneration. Invest Ophthalmol Vis Sci 41:4293-4299

21. Samardzija M, von Lintig J, Tanimoto N et al (2008) ARG91TRP mutation in Rpe65 leads to milder early-onset retinal dystrophy due to the generation of low levels of 11-cis-retinal. Hum Mol Genet 17:281-292

22. Jacobson SG, Cideciyan AV, Aleman TS et al (2008) Photoreceptor layer topography in children with leber congenital amaurosis caused by RPE65 mutations. Invest Ophthalmol Vis Sci 49:4573-4577
23. Russell S, Bennett J, Wellman JA et al (2017) Efficacy and safety of voretigene neparvovec (AAV2-hRPE65v2) in patients with RPE65-mediated inherited retinal dystrophy: a randomised, controlled, open-label, phase 3 trial. Lancet 390:849-860

24. Klein M, Birch DG (2009) Psychophysical assessment of low visual function in patients with retinal degenerative diseases (RDDs) with the Diagnosys full-field stimulus threshold (D-FST). Doc Ophthalmol 119:217-224

Publisher's Note Springer Nature remains neutral with regard to jurisdictional claims in published maps and institutional affiliations. 